\title{
Water electrolyzer for renewable energy systems
}

\author{
Kuleshov V. $N^{1^{*}}$, Kuleshov N. $V^{1}$, Kurochkin S. $V^{1}$, Fedotov A. $A^{1}$, Sleptsova E. $E^{1}$, Blinov D. $V^{1,2}$, Gavriluk $A . A^{1}$ and \\ Zhmurko I. E \\ ${ }^{1}$ National Research University «Moscow Power Engineering Institute» Moscow, Russia \\ ${ }^{2}$ Joint Institute of High Temperature, Russian Acadimy of Science, Moscow, Russia
}

\begin{abstract}
The article is devoted to the features of the alkaline water electrolyzers use in power plants with a hydrogen energy storage systems based on renewable energy sources. The technology of nickel-cobalt electrodes electrochemical formation according to a printed 2-dimensional sketch is proposed. A new technique for the synthesis of diaphragms with a zirconium hydroxide hydrogel as a hydrophilic filler is considered. The current-voltage characteristics of an electrolytic cell located inside outer containment shell, designed for pressures up to $160 \mathrm{~atm}$, are investigated.
\end{abstract}

Keywords: alkaline water electrolysis, nickel-cobalt electrodes, polymer-based diaphragm, hydrogel hydrophilic filler, electrolysis cell, outer containment shell

\section{Features of water electrolyzers for renewable energy systems}

Power plants with a hydrogen energy storage systems (HESS), including based on renewable energy sources (RES), are one of the most promising areas for the development of world energy [1]. The key elements of HESS are water electrolyzer, hydrogen (sometimes oxygen) storage system, and fuel cell system. The water electrolyzer generates hydrogen (and oxygen) from the excess electrical energy of the primary source. Depending on the final user and it's needs, the generated hydrogen can be stored in a compressed form, liquefied state, on various carriers, for example, metal hydrides, capillaries, microspheres and carbon materials. The processes of reversible hydrogenation of unsaturated hydrocarbons open up great prospects for safe storage and transportation. The lack or absence of electrical energy from the primary source is compensated by a system of fuel cells that convert the chemical energy of the reaction between stored hydrogen and oxygen (from oxygen storage system or air) back into electrical energy.

The HESS use low-temperature alkaline water electrolizers (AWE) or electrolyzers with polymer electrolyte membrane (PEM). The advantages of AWE are the absence of platinum group metals in the catalyst compositions, the lower cost of diaphragm materials in comparison with polymer electrolyte membranes, and the possibility of cold start at negative temperatures (from $-40{ }^{\circ} \mathrm{C}$ ). As the experience of operating actually created power plants based on renewable energy sources shows, AWE produced by the modern industry have a number of significant drawbacks in terms of HESS use
[2]. Modern industrial AWE electrolyzers do not provide the necessary purity of the generated gases at a minimum (less than $25 \%$ of the nominal capacity) and maximum generation of electrical energy by the primary source. In order to avoid cross-contamination of gases, the electrolyzer is turned off, and it takes a long time to restart it (at least 30-60 minutes). The use of industrial AWE in HESS leads to significant losses of electrical energy, which sharply reduces the energy efficiency of HESS as a whole. Another drawback is that the pressure at the outlet of the AWE is limited to 10-30 atm, which is insufficient for most hydrogen storage systems. As a rule, booster compressors are used to increase the amount of stored hydrogen, regardless of storage system type, which also increases the cost and reduces the energy efficiency and reliability of HESS. For the successful implementation of AWE electrolyzers in HESS, it is necessary to expand the range of capacities, reduce energy consumption and increase the working pressure directly at the outlet of the electrolyzer [3].

\section{Electrodes for AWE}

Despite the absence of the platinum group metals, the problem of reducing the cost and increasing the efficiency of electrodes for AWE remains relevant. As a result of research, a 2-d technology of electrochemical formation of electrodes based on an inkjet printer sketch has been developed, Fig. 1. This technology allows manufacture electrodes of any configuration, varying thickness from 0.2 to $4 \mathrm{~mm}$, the cells size and geometry. The electrodes cost is several times less than that of braided nickel grids or laser-cut electrodes.

* Corresponding author: KuleshovVLN $@$ mpei.ru 


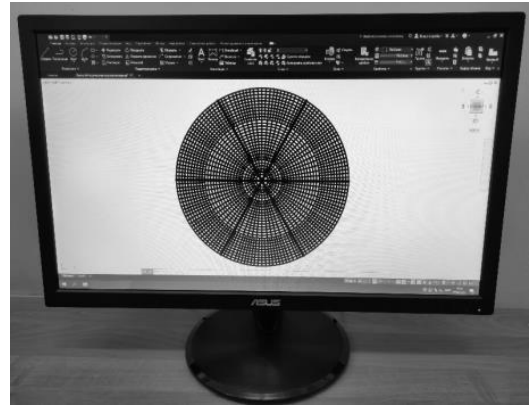

a

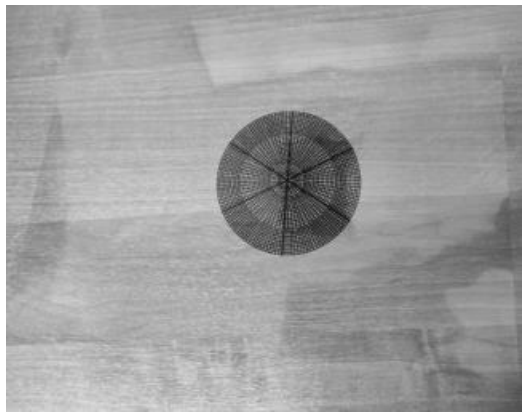

b

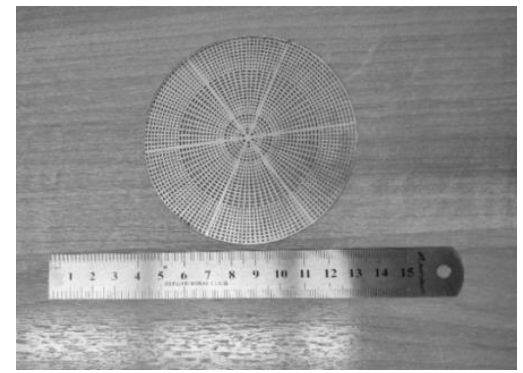

Fig. 1. 2-d technology manufacturing of nickel-cobalt electrodes for AWE: $a-2 d$ sketch $b$ - sketch, printed on transparent film, $\mathrm{c}$ - nickel-cobalt electrode.

To increase the electrochemically active electrode surface, a porous nickel-cobalt coating was formed on its surface by co-deposition of a submicron nickelcobalt powder and an electrolytic nickel-cobalt alloy. Submicron Ni-Co powders were prepared by thermal decomposition of mixed nickel and cobalt formate in a 1,4-butanediol medium according to reactions (1-2):

$\mathrm{Me}(\mathrm{HCOO})_{2} \rightarrow \mathrm{Me}+\mathrm{CO}+\mathrm{CO}_{2}+\mathrm{H}_{2} \mathrm{O}$, (1)

$\mathrm{Me}(\mathrm{HCOO})_{2} \rightarrow \mathrm{Me}+2 \mathrm{CO}_{2}+\mathrm{H}_{2}$, (2)

$\mathrm{Me}=\mathrm{Ni}$ and $\mathrm{Co}$

Powder is pyrophoric and instantly oxidized at contact with air oxygen. Therefore, it was transferred to an electroplating bath as a suspension in 1,4-Butanediol. 1,4-Butanediol is one of the standard scattering additives for nickel plating electrolyte, allowing for more uniform coatings.

The formation of a porous electrode coating was carried out in a galvanic bath from an electrolyte containing (g/l): nickel sulfate $\left(\mathrm{NiSO}_{4} \cdot 7 \mathrm{H}_{2} \mathrm{O}\right)-350$; nickel chloride $\left(\mathrm{NiCl}_{2} \cdot 6 \mathrm{H}_{2} \mathrm{O}\right)-60$, cobalt sulfate $\left(\mathrm{CoSO}_{4}\right)-170$, cobalt chloride $\left(\mathrm{CoCl}_{2}\right)-30$, boric acid
$\left(\mathrm{H}_{3} \mathrm{BO}_{3}\right)-60$, suspension of $\mathrm{Ni}-\mathrm{Co}$ powder and 1,4 butanediol with nickel and cobalt anodes.

Fig. 2 shows a micrograph of the electrode porous coating. Particles of $\mathrm{Ni}-\mathrm{Co}$ powder synthesized by thermal decomposition of mixed nickel and cobalt formates have an acicular structure. In the process of deposition, the particles are enlarged and their reliable fixation on the surface occurs due to the electrochemically deposited nickel and cobalt alloy.

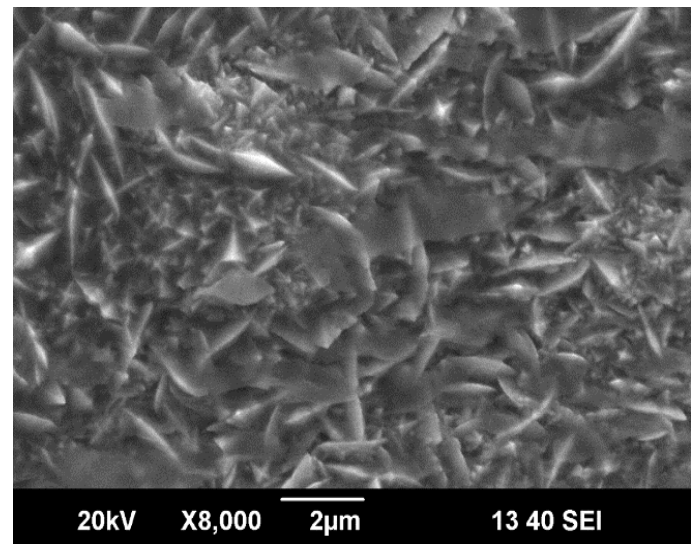

Fig. 2. Porous nickel-cobalt electrode coating micrograph.

Nickel-cobalt electrodes with a porous nickel-cobalt coating were additionally modified with catalysts of cathodic and anodic processes. The cathodic catalyst $\left(\mathrm{Ni}-\mathrm{Co}-\mathrm{P}_{\mathrm{x}}\right)$ was applied by chemical reduction of nickel-cobalt-phosphorus from a solution of nickel and cobalt chlorides with sodium hypophosphite at $40^{\circ} \mathrm{C}$ according to reactions (3-5):

$\mathrm{NaH}_{2} \mathrm{PO}_{2}+\mathrm{H}_{2} \mathrm{O}=\mathrm{NaH}_{2} \mathrm{PO}_{3}+2 \mathrm{H}_{\text {atomic }}(3)$

$\mathrm{Me}^{2+}+2 \mathrm{H}_{\text {atomic }} \rightarrow \mathrm{Me}+2 \mathrm{H}^{+}$(4)

$8 \mathrm{H}_{2} \mathrm{PO}_{2}+2 \mathrm{H}_{2} \mathrm{O}+2 \mathrm{H}^{+} \rightarrow 2 \mathrm{P}+6 \mathrm{H}_{2} \mathrm{PO}^{-}+5 \mathrm{H}_{2}(5)$

$\mathrm{Me}=\mathrm{Ni}$ или $\mathrm{Co}$

The anodic catalyst, nickel-cobalt spinel $\left(\mathrm{NiCo}_{2} \mathrm{O}_{4}\right)$ was applied by thermal decomposition of an alcohol solution of $\mathrm{Ni}\left(\mathrm{NO}_{3}\right)_{2}$ and $\mathrm{Co}\left(\mathrm{NO}_{3}\right)_{2}$ taken in a molar ratio of 1:2 according to the reaction (6):

$\mathrm{Ni}\left(\mathrm{NO}_{3}\right)_{2}+2 \mathrm{Co}\left(\mathrm{NO}_{3}\right)_{2} \rightarrow \mathrm{NiCo}_{2} \mathrm{O}_{4}+6 \mathrm{NO}_{2}+\mathrm{O}_{2}$

An electrode with a porous nickel-cobalt coating was immersed in an alcohol solution of nickel and cobalt nitrates, placed in a quartz tube, heated to a temperature of $250^{\circ} \mathrm{C}$, held for 2 hours, then the temperature was increased at a rate of $1{ }^{\circ} \mathrm{C} / 5$ minutes to $300{ }^{\circ} \mathrm{C}$ and additionally stood for another 3 hours. To form a dense catalyst layer, the operation was repeated 3-5 times [4].

Comparison of the cathodic catalysts polarization curves (Fig. 3a) shows that the braided nickel grid (curve 1) and the developed $\mathrm{Ni}-\mathrm{Co}$ electrode (curve 2) have similar activity and, judging by the Tafel slope curve the reaction mechanism does not change. The porous $\mathrm{Ni}-$ Co coating (curve 3 in Fig. 3a) allows to reduce the hydrogen evolution reaction overvoltage by $120 \mathrm{mV}$ at $300 \mathrm{~mA} / \mathrm{cm}^{2}$, and additional modification with a Ni-Co$\mathrm{P}_{\mathrm{x}}$ catalyst by another $180 \mathrm{mV}$ in comparison with an uncoated $\mathrm{Ni}-\mathrm{Co}$ electrode.

In the anodic processes the $\mathrm{Ni}-\mathrm{Co}$ electrode is more active than the braided nickel mesh (curves 1 and 2 in Fig. 3b). The change in the slope of the polarization 
curve may indicate a change in the reaction mechanism. Electrodes with a porous $\mathrm{Ni}-\mathrm{Co}$ coating make it possible to reduce the oxygen evolution reaction overvoltage by $150 \mathrm{mV}$ at $300 \mathrm{~mA} / \mathrm{cm}^{2}$ (curve 3 in Fig. 3 b) compared to an uncoated $\mathrm{Ni}$ - Co electrode. Additional modification with nickel-cobalt spinel $\left(\mathrm{NiCO}_{2} \mathrm{O}_{4}\right)$ reduce the overvoltage by $210 \mathrm{mV}$ at $300 \mathrm{~mA} / \mathrm{cm}^{2}$ (curve 3 in Fig. $3 b)$ compared to an uncoated $\mathrm{Ni}-\mathrm{Co}$ electrode.

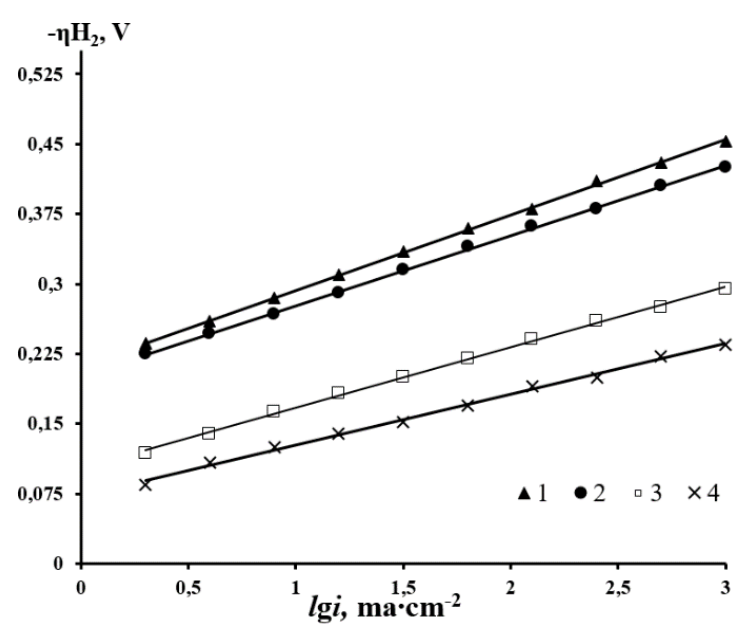

a

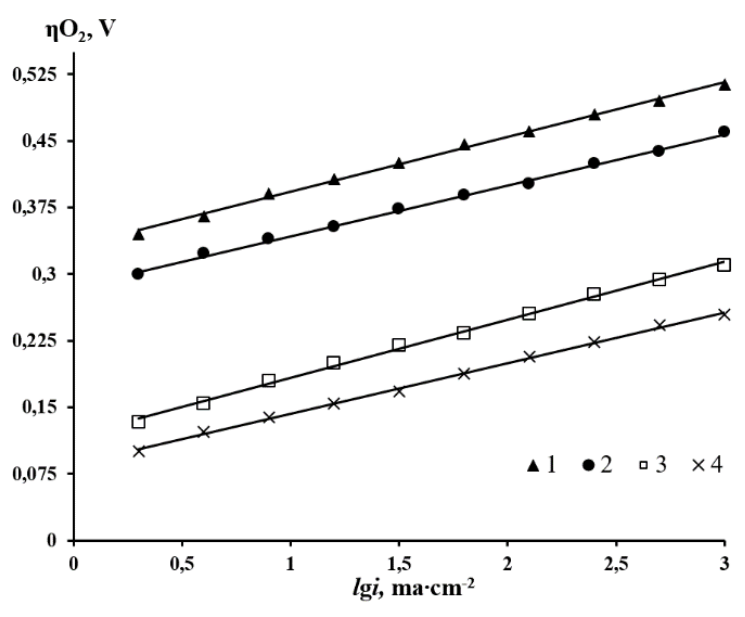

b

Fig. 3. Polarization curves: a - hydrogen evolution reaction (1 - braided nickel mesh; 2 - Ni - Co electrode without coating; $3-\mathrm{Ni}-\mathrm{Co}$ electrode with porous $\mathrm{Ni}-\mathrm{Co}$ coating; $4-\mathrm{Ni}-\mathrm{Co}$ electrode with porous $\mathrm{Ni}-\mathrm{Co}$ coating modified with $\mathrm{Ni}-\mathrm{Co}-$ $\mathrm{P}_{\mathrm{x}} ; \mathrm{b}$ - oxygen evolution reaction ( 1 - braided nickel mesh; 2 $\mathrm{Ni}-\mathrm{Co}$ electrode without coating; $3-\mathrm{Ni}-\mathrm{Co}$ electrode with porous $\mathrm{Ni}-\mathrm{Co}$ coating; $\mathrm{Ni}-\mathrm{Co}$ electrode with porous $\mathrm{Ni}-$ Co coating modified $\mathrm{NiCO}_{2} \mathrm{O}_{4}$ ).

\section{Polymer - based diaphragms for AWE}

The main disadvantages of AWE, limiting their operation with minimum and maximum production of electrical energy by the primary source, are associated with the porous structure of the diaphragm material. Unlike PEM electrolyzers, where protons $\left(\mathrm{H}^{+}\right)$are transferred along the ionogenic sulfonic acid groups of the polymer electrolyte membrane, in AWE electrolyzers, the internal electric circuit is closed by the transfer of hydroxyl ions $\left(\mathrm{OH}^{-}\right)$due to the free movement of the electrolyte $(\mathrm{KOH})$ through the porous diaphragm.

At low current densities (up to $100 \mathrm{~mA} / \mathrm{cm}^{2}$ ), small gas bubbles are formed that can penetrate through the diaphragm. At high current densities (more than 700 $\mathrm{mA} / \mathrm{cm}^{2}$ ), the probability of gas bubbles penetration through the diaphragm increases due to the high electrolyte gas filling. Limitations on the maximum working pressure are also associated with the porous structure of the diaphragm material, since when it increases (80 atm and above), the solubility of gases in the electrolyte increases and the purity of the generated gases decreases.

Recent years, a number of publications have appeared on anion-exchange membranes for AWE [5]. Many articles are devoted to the study of the commercially available anion-exchange membranes properties produced under the trademarks Sustanion (Dioxide Materials, FL, USA), A-201 (Tokuyama, Japan) and AEMION (Ionomr, Canada). Nanoporous or non-porous anion-exchange membranes open up broad prospects for increasing the operating pressure of the AWE and eliminating the minimum and maximum power thresholds. These materials represent a polymer chain where the transfer of the hydroxyl ion is carried out along the ionogenic groups of quaternary amines, amides, imides, and their combination. This type of material has proven itself well in water treatment processes, but chemical resistance at AWE electrolysis conditions is questionable. In order to reduce energy consumption of industrial AWE, a 6-8M KOH solutions are used as the electrolyte, and the operating temperature is $80,100,120{ }^{\circ} \mathrm{C}$. Manufacturers of anion exchange membranes limit the electrolyte concentration up to 1-2 $\mathrm{M} \mathrm{KOH}$, and the operating temperature to $40-60^{\circ} \mathrm{C}$. Even under these conditions, the confirmed resource is several days, which is not enough for real AWE and HESS [6].

In this work, we investigated two types of diaphragms for AWE. Diaphragm 1 is a close analog of the industrially produced ZirfonPearl (Agfa) diaphragms [7]. These are the most tested under alkaline water electrolysis conditions diaphragms, based on porous polymer-based matrix with the addition of a hydrophilic filler titanium dioxide $\left(\mathrm{TiO}_{2}\right)$ or zirconium dioxide $\left(\mathrm{ZrO}_{2}\right)$, synthesized by the phase inversion method.

Alkali-resistant polysulfone PSF-150 (close analog Udel) was dissolved in an aprotic organic solvent (dimethylacetamide), and a hydrophilic filler, finely dispersed titanium dioxide $\left(\mathrm{TiO}_{2}\right)$, was added. The resulting formation solution was applied to a polymer reinforcing mesh and immersed in a coagulation bath filled with water. Phase inversion occurs in the coagulation bath, replacement of an organic solvent with a non-solvent (water), accompanied by the fixation of polymer chains and the formation of a porous polymer matrix filled with particles of a hydrophilic filler [8]. The content of the hydrophilic filler in the finished 
diaphragm is: diaphragm $1-\mathrm{TiO}_{2} 70$ wt. \%, ZirfonPearl $-\mathrm{ZrO}_{2} 85$ wt. \%.

As an alternative, a new diaphragm 2 is proposed. The pores of diaphragm 2 are filled with zirconium hydroxide hydrogel. Polysulfone PSF-150 was dissolved in an aprotic solvent (tetrahydrofuran) and applied to a mesh support. The coagulation bath was filled with a solution of zirconium oxychloride $\mathrm{ZrOCl}_{2}$ in ethyl alcohol. In the coagulation bath, phase inversion occurs, the formation of a porous polymer matrix and the filling of the pores with a zirconium oxychloride solution. When boiling the impregnated polymer matrix in a $6 \mathrm{M}$ $\mathrm{KOH}$ solution, ethyl alcohol is washed out, zirconium oxychloride is hydrolyzed, and the pores of the diaphragm are filled with $\mathrm{ZrO}_{x}(\mathrm{OH})_{2-\mathrm{x}}$ hydrogel. For comparison, a diaphragm was made that did not contain any hydrophilic filler and was coagulated in ethyl alcohol.

Fig. 4 schematically shows the internal structure of diaphragm 1, diaphragm without hydrophilic filler and diaphragm 2.

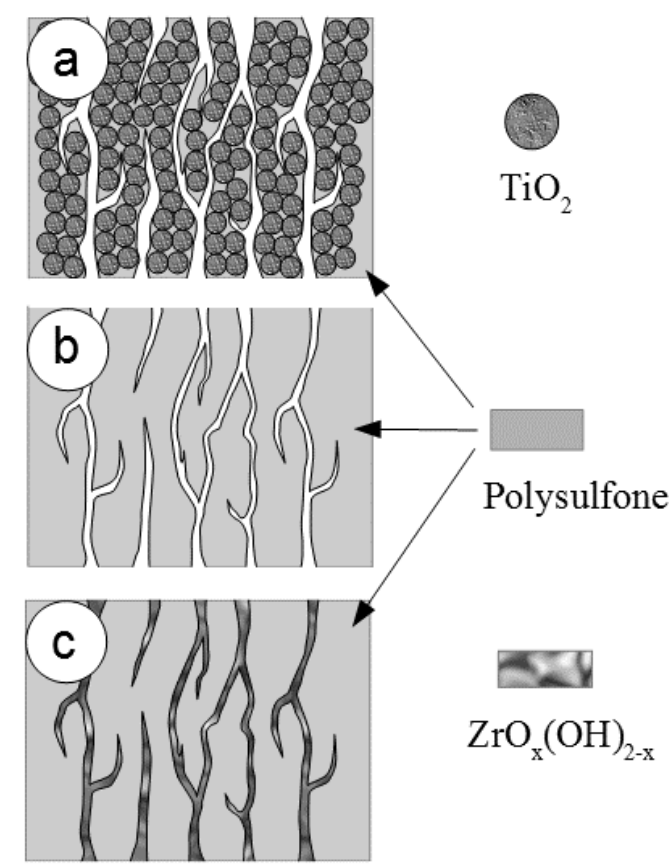

Fig. 4. Internal structure of diaphragm materials: a diaphragm 1, hydrophilic filler - $\mathrm{TiO}_{2} 70 \%$, analogue of ZirfonPearl; b - diaphragm without a hydrophilic filler; c diaphragm 2, hydrophilic filler $-\mathrm{ZrO}_{\mathrm{x}}(\mathrm{OH})_{2 \text {-x }}$ hydrogel.

The total porosity and integral pore radius distribution of diaphragm 1 obtained by contact-reference porosimetry method is shown in Fig. 5. This method does not allow distinguishing water that freely fills the diaphragm from water bound in hydrogel globules. For an indirect assessment of diaphragm 2 porosity, we used the results for a diaphragm matrix without a hydrophilic filler.

The porosity, electrical conductivity and gas permeability of diaphragms (by the method "bubble point pressure") are shown in Table 1. For comparison, the characteristics of the ZirfonPearl diaphragms are given.

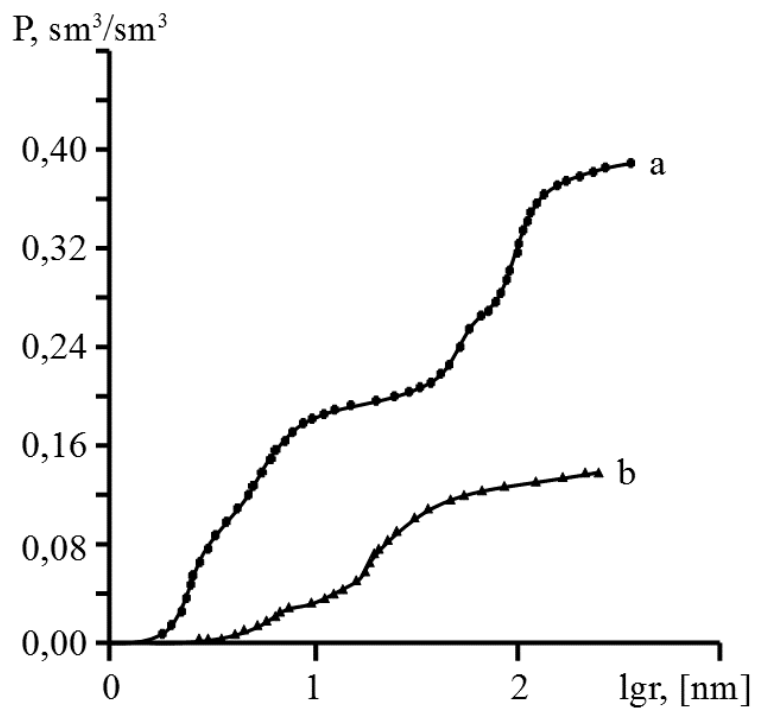

Fig. 5. Integral distribution of pores radius: $a-$ diaphragm 1; b - diaphragm without hydrophilic filler.

Table 1. Characteristics of diaphragm materials for AWE.

\begin{tabular}{|l|c|c|c|c|}
\hline Diaphragm & $\begin{array}{c}\text { Total } \\
\text { porosity } \\
\mathrm{P} \\
\mathrm{sm}^{3} / \mathrm{sm}^{3}\end{array}$ & $\begin{array}{c}\text { Max. } \\
\text { pore } \\
\text { radius, } \\
\mathrm{nm}\end{array}$ & $\begin{array}{c}\text { Sp. electrical } \\
\text { conductivity } \\
6 \mathrm{M} \mathrm{KOH}, \\
80^{\circ} \mathrm{C}, \\
\kappa, \mathrm{Ohm}^{-1} \mathrm{sm}^{-1}\end{array}$ & $\begin{array}{c}\text { Bubble } \\
\text { point } \\
\text { pressure, } \\
\text { atm }\end{array}$ \\
\hline Diaphr. 1 & 0,38 & 90 & 0,270 & 3,4 \\
\hline $\begin{array}{l}\text { Diaphr. } \\
\text { without } \\
\text { hydrophilic } \\
\text { filler }\end{array}$ & 0,16 & 30 & - & 4,4 \\
\hline Diaphr. 2 & - & - & 0,220 & 5,6 \\
\hline ZirfonPearl & 0,50 & 130 & 0,292 & 2,5 \\
\hline
\end{tabular}

As it shown at Fig. 4, 5 and in Table 1, diaphragm 1 $\left(\mathrm{TiO}_{2}\right)$ and $\mathrm{ZirfonPearl}\left(\mathrm{ZrO}_{2}\right)$ have a biporous structure, in which electrolyte transfer is possible both through the pores of the polymer matrix and through particles of the hydrophilic filler. The specific electrical conductivity and gas permeability of the diaphragm 1 is lower than that of ZirfonPearl, which can be explained by the lower amount of hydrophilic filler. Diaphragm 2, in comparison with diaphragm 1 , is characterized by 2 times lower total porosity and 3 times smaller pore radius. Diaphragm 2 is characterized by the lowest specific electrical conductivity, since there is no (or extremely difficult) free transport of electrolyte through the pores. Considering that zirconium hydroxides have amphoteric properties, in alkaline media, it can be assumed that charge transfer occurs due to the migration of hydroxyl ions between hydrogel globules, that is, electrical conductivity may be due to anion exchange. The advantage of diaphragm 2 is its low gas permeability, which opens up broad prospects for its use in AWE for HESS.

Diaphragms with zirconium hydroxide hydrogel as hydrophilic filler have demonstrated their applicability in AWE processes, and further studies should be carried out in order to establish correlation dependences of the generated gases purity on the synthesis conditions, 
pressure and temperature, as well as life tests taking into account possible aging processes of the hydrogel.

\section{Design of AWE electrolysis modules, studies of volt-ampere characteristics}

The electrolysis process makes it possible to generate hydrogen and oxygen under high pressure directly at the outlet of the electrolysis module without the use of booster compressors. Traditionally, in industrial electrolyzers, electrolysis modules of a planar design are used, operating in the pressure range of 1-30 atm. To create an efficient power plant based on RES and HESS, the pressure should be 100-300 atm, and in the future up to $700 \mathrm{~atm}$

The problem of pressure increase can be solved by replacing one high-performance electrolysis module with several modules of lower performance in outer containment shell, which allows reaching pressures up to 100-200 atm with the same total productivity, or by a series of electrolysis cells of coaxial design (300 atm, in the future up to $700 \mathrm{~atm}$ ) [9], Fig. 6. In addition to increasing the pressure, this solution allows to significantly lower the minimum power capacity of the AWE not only by reducing the current density, but also by stepwise disconnection of individual modules.

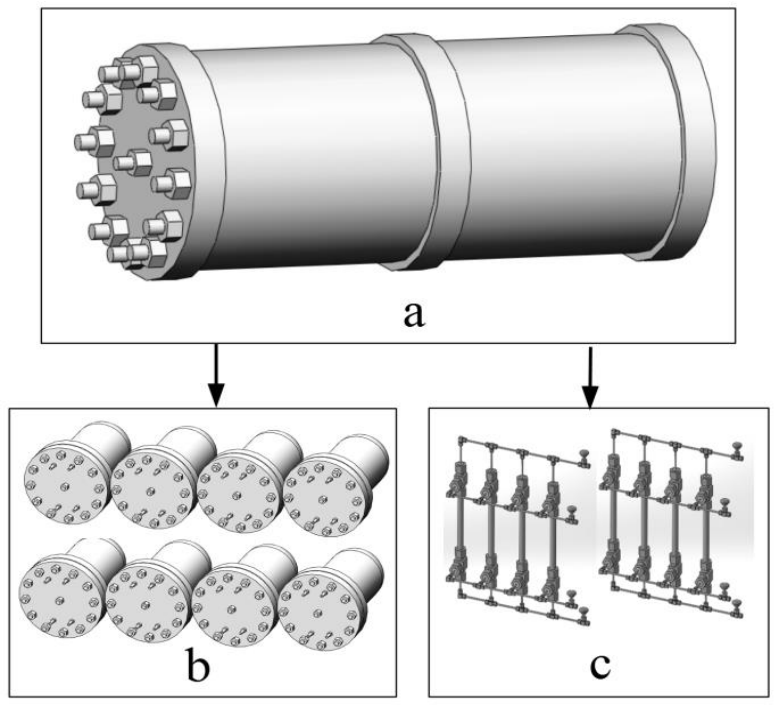

Fig. 6. AWE modules layout: a - single high-performance planar module, $1-30 \mathrm{~atm}$; $\mathrm{b}$ - several low performance planar modules in outer containment shell, 100-200 atm; c - series of coaxial design electrolysis cells, 300-700 atm.

The main disadvantage of the outer containment shell is its high mass and dimensional characteristics. For example, at a pressure up to 100 atm, the mass ratio electrolysis module: outer containment shell is $1: 40$, for a pressure up to $160 \mathrm{~atm}-1: 50$, and for a pressure up to $200 \mathrm{~atm}-1: 90$. As a rule, this design is used for special (space or defense) applications, laboratory research and for HESS with electrical capacity of up to $1-5 \mathrm{~kW}$.

In this work, to study the volt-ampere characteristics of the electrolysis module, we used an outer containment shell designed for pressures up to $160 \mathrm{~atm}$, Fig. 7. The studies were carried out for an electrolysis cell with a working diameter of electrodes $70 \mathrm{~mm}$ at a temperature of $80{ }^{\circ} \mathrm{C}$ and pressures of 1,30 , and 100 atm. The pressure equalization inside and outside the electrolysis battery was carried out by supplying the hydrogen generated during the electrolysis to the inside of the outer containment shell.

Volt-ampere curves (Fig. 8) show that as the pressure increases from 1 to 30 atm, the cell voltage decreases for any diaphragm type. Probably these results can be explained by a decrease in the depolarization of the electrodes and a decrease electrolyte gas filling. With a further increase of a pressure from 30 to $100 \mathrm{bar}$, the voltage increases, that corresponds to thermodynamic calculations.
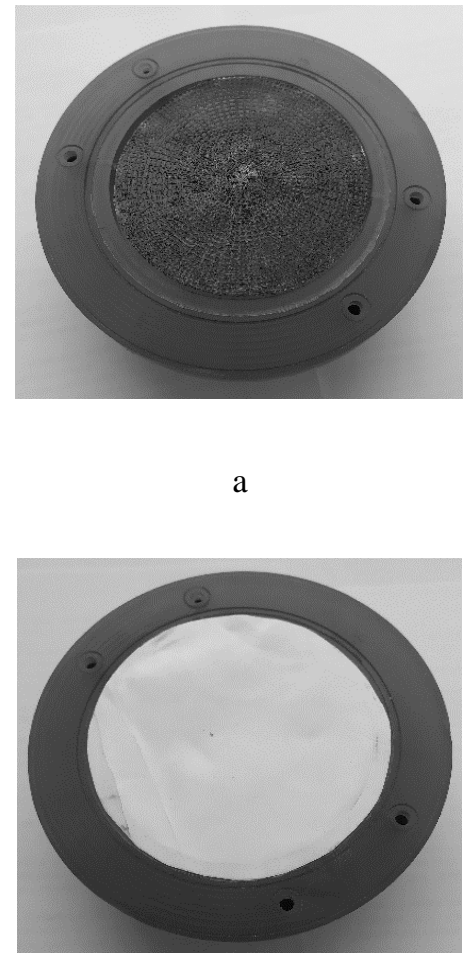

b

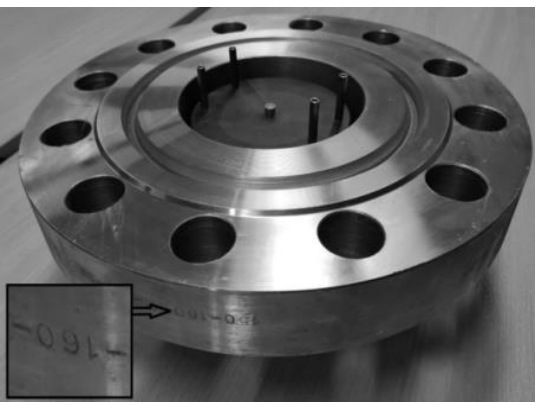

Fig. 7. Low performance planar module in outer containment shell (up to $160 \mathrm{~atm}$ ): a - porous coated anode, modified $\mathrm{NiCO}_{2} \mathrm{O}_{4}$ catalyst; b - polymer-based diaphragm; c electrolysis cell installed inside of the outer containment shell. 


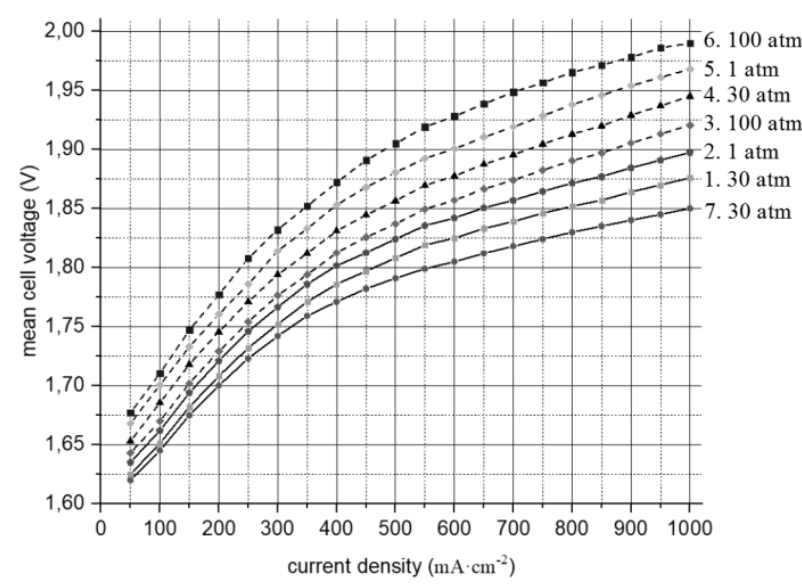

Fig. 8 Volt-ampere characteristics of electrolysis cells: 1-3 diaphragm 1;4-6-diaphragm 2; 7 -ZirfonRearl.

As it was expected, electrolytic cells with ZirfoneRearl and Diaphragm 1 have the lowest voltage. This type of diaphragm provides the lowest energy consumption of industrial AWE operating at pressures up to $30 \mathrm{~atm}$. New diaphragms with zirconium hydroxide hydrogel, allow in the future to increase the energy efficiency of HESS as a whole, by increasing the purity of the generated gases, the pressure at the outlet of the electrolysis module, expansion the range of capacities from RES, and the rejection of peripheral devices such as booster compressors and gas purification systems.

\section{Conclusions}

Described new techniques and materials make it possible to create a new highly efficient AWE for use in RES with HESS. Methods of an electrodes forming of a given two-dimensional geometry and chemical composition, methods of developing an electrochemically active surface and additional modification of cathodic and anodic catalysts allow reduce cost, improve energy efficiency and reduce energy consumption AWE. A new technique for the synthesis of polymer-based diaphragms with a zirconium hydroxide hydrogel as a hydrophilic filler for AWE for HESS is presented. Despite the lower electrical conductivity, the new type of diaphragm in the future will significantly improve the purity of the generated gases. A number of design solutions have been proposed to create a high-pressure electrolysis module (100-300 atm). The current-voltage characteristics of an electrolysis cell with new electrodes and diaphragm materials have been investigated. The sum of the given data makes it possible to eliminate the shortcomings of industrial AWE and increase the energy efficiency of power systems with HESS, including those based on RES.

The studies were carried out within the framework of the Scientific Research Program of the National Research University "Moscow Power Engineering Institute". SRP 2020/22 "Energy, Stage II", section 5 "Hydrogen energy". Project "High efficient electrolyzer with a hydrogen storage system for power plants based on renewable sources with a hydrogen energy storage systems".

\section{References}

1. https://ec.europa.eu/commission/presscorner/detail/e n/qanda 20_1257

2. Oystein Ulleberg, Torgeir Nakken, Arnaud Ete, Int. J. Hydrogen Energy 35 (2010)

3 N.V. Kuleshov, V.N. Kuleshov, S.A. Dovbysh, S.A. Grigoriev, S.V. Kurochkin, P. Millet Int. J Hydrogen Energy 44, 56 (2019)

4 V.N. Kuleshov, N.V. Kuleshov, S.V. Kurochkin, Russ. J. Appl. Chem. 93, 8 (2020)

5 I. Vincent, D. Bessarabov, Renew Sust. Energ. Rev. 81 (2018)

6 M. Hickner, A. Herring, B. Coughlin, J. Polym. Sci., Part B: Polym. Phys.. Part B 51 (2013)

7 https://www.agfa.com/specialtyproducts/solutions/membranes/zirfon/

8 N. V. Kuleshov, V. N. Kuleshov, S. A. Dovbysh, E. Ya. Udris, S. A. Grigor'ev,Yu. A. Slavnov, L. A. Korneeva Russ. J. Appl. Chem. 89, 4 (2016)

9 V. N. Kuleshov, S. V. Kurochkin, N. V. Kuleshov and E. Ya. Udris, J Phys Conf Ser. 1683 (2020) 